\title{
A SEMIÓTICA COMO ALTERNATIVA EPISTEMOLÓGICA NAS PES- QUISAS EM CONTABILIDADE
}

SEMIOTICS AS AN EPISTEMOLOGICAL ALTERNATIVE IN ACCOUNTING RESEARCH

\section{Sheila Sayuri Kataoka', Paulo Henrique Leal ${ }^{2}$}

RECEBIDO: 02/11/2019 | ACEITO: 07/11/2019

DOI: $10.5902 / 2317175840908$

\section{RESUMO}

Os conceitos que servem de base de sustentação para contabilidade são socialmente construídos, não podendo ser medidos e apresentados apenas de maneira quantitativa, por esse motivo, alguns pesquisadores, tais como Williams (2014), Walker (2016), Major (2017), defendem iniciativas de abordagens alternativas ao maistream. Assim, o presente artigo discutiu a semiótica como uma proposta de alternativa epistemológica nas pesquisas em contabilidade. Por meio de uma abordagem ensaística na qual referencial baseado em outros estudos e análise interpretativa se complementaram, verificou-se que é possível posicionar a semiótica Peirceana como uma abordagem alternativa de pesquisa, de forma que essa seja considerada como uma iniciativa que reconheça a contabilidade dentro do contexto sociológico e que observa as caraterísticas intrínsecas à realidade dos fenômenos. Espera-se, com o resultado dessa pesquisa, contribuir para o debate das alternativas de pesquisa em contabilidade dentro de um contexto multidisciplinar de investigação científica.

Palavras-chave: Semiótica; Epistemologia; Maistream; Contabilidade.

1 Professora Adjunta do Departamento de Finanças e Contabilidade da Universidade Federal da Paraíba. Doutoranda do Programa de Pós-Graduação em Ciências Contábeis da Universidade Federal de Pernambuco. 


\section{ABSTRACT}

The concepts that support the accounting base are socially constructed and cannot be measured and presented only quantitatively, so some researchers, such as Williams (2014), Walker (2016), Major (2017), argue initiatives for alternative approaches to maistream. Thus, the present paper discussed semiotics as a proposal for an epistemological alternative in accounting research. Through an essayistic approach in which reference based on other studies and interpretative analysis complemented each other, it was found that it is possible to position Peircean semiotics as an alternative research approach, so that it is considered as an initiative that recognizes accounting within of the sociological context and that observes the intrinsic characteristics to the reality of the phenomena. This research is expected to contribute to the debate on accounting research alternatives within a multidisciplinary context of scientific research.

Keywords: Semiotics; Epistemological; Maistream; Accounting.

\section{Introdução}

O objetivo desse artigo é discutir a semiótica como uma proposta de alternativa epistemológica nas pesquisas em contabilidade. As pesquisas em contabilidade, a partir da década de 70, passaram a ter como paradigma dominante o positivismo e o empírismo, no entanto esses tipos de pesquisas têm sido criticadas por diversos pesquisadores como: Hopwood (2007), Williams (2014), Walker (2016), Major (2017), entre outros, que defendem abordagens alternativas ao mainstream. Uma das justificativas para a agregação de abordagens diferenciadas é a posibilidade de responder as questões dos tipos 'por quê?' 'como?' permitindo a compreensão e explicação profunda do fenômeno.lsto difere do que ocorre no positivismo, em que há a descrição e identificação de regularidades do que é observado, impedindo a consideração de questões que metodologicamente não se insiram em uma realidade concreta, objetiva e que não possam ser expressas numericamente (HOPWOOD, 2007; MAJOR, 2017).

Assim, investigações no domínio da contabilidade consideradas com abordagens alternativas são aquelas caracterizadas por uma diversidade metodológica.A exemplo da pesquisa interpretativa e da pesquisa crítica, que têm sido incentivadas por alguns pesquisadores, como também a adoção de uma abordagem metodológica qualitativa de pesquisa, alicerçada em teorias organizacionais e sociológicas respaldadas pelo contexto social em que a ciência está pautada (WALKER, 2016).

Na busca de abordagens alternativas, no presente artigo, a semiótica, mais especificamente a filosófia de Peirce, será apresentada como uma posição epistemológica defendida por alguns pesquisadores, tais como: Kremer (1994), Santos (2001), Wasik (2014) e Silva (2015). Este último argumenta que: "por sua abrangência e rigor lógico, a semiótica guarda possibilidades de aplicação que vão além da linguagem e dos processos comunicativos, estendendo-se à ciência como um todo, o que possibilita a organização de uma nova epistemologia". Ao posicionar a contabilidade na esfera sócio econômica como um instrumento de apoio à ordem social, Nakagawa e Dias Filho (2002, p. 13) consideram que a semiótica pode fornecer metodologias úteis para avaliar a eficácia do ato comunicativo e facilitar a apresentação de informações significativas para diversos usuários.

A semiótica no contexto da contabilidade como uma linguagem informacional é investigada por diversos pesquisadores. Como por exemplo, Etheridge (1991), Hronsky (1998), Ilufi (2000), Nakagawa e Pretto (2000), Nakagawa e Dias Filho (2012), Messias (2017), dentre outros, que buscaram demonstrar a semiótica como contribuição para melhoria da comunicação das funções da contabilidade; bem como, outros estudos identificaram publicações da área contábil com foco na semiótica a exemplo de Gouveia (2010) e Fontana et al (2013). No entanto, no contexto contábil observou-se a existência de uma lacuna na discussão entre a assunção da semiótica como posição epistemológica e sua contribuição para as pesquisas alternativas; assim, o presente artigo busca responder ao seguinte questionamento: De que forma a semiótica pode ser utilizada como uma alternativa de abordgem epistemológica nas pesquisas em contabilidade?

A questão aqui apresentada foi respondida a partir de uma abordagem ensaística, na qual referencial baseado em outros estudos e análise interpretativa se complementam. Espera-se como resultado dessa pesquisa contribuir para o debate das alternativas de pesquisa em contabilidade apresentando e discutindo a visão da semiótica como uma possibilidade epistemológica para a investigação científica.

Para o desenvolvimento desse artigo, este encontra-se dividido em outras cinco seções além dessa introdução. A seção 2 apresenta uma breve explicação sobre a semiótica desde a raiz etimológica até a sua relação com as demais ciências; a seção 3 aborda a visão da contabilidade como uma linguagem e como esta se relaciona com a semiótica, evidenciando algumas pesquisas da área; a seção 4 trata sobre os principais argumentos defendidos por filósofos $\mathrm{e}$ pesquisadores que consideram a semiótica de Peirce como uma posição epistemológica. Na seção 5 é discutida a semiótica como uma alternativa epistemológica nas pesquisas em contabilidade; e por fim, na última seção apresenta as considerações finais a respeito.

\section{Breve Explicação sobre a Semiótica}

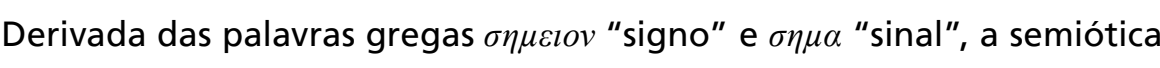
tem a raiz $\sigma \varepsilon \mu \varepsilon$ "seme" como em semeiotikos (interprete dos signos). Assim, a semiótica é comumente conceituada como a ciência dos signos. O signo pode ser entendido como um sinal verbal por meio do qual se representa alguma coisa. Este pode ser um objeto perceptível ou apenas imaginável, ou até mesmo inimaginável em algum sentido; como também uma idéia ou uma cognição. O signo está presente para designar ou significar outra coisa ausente, concreta ou abstrata (NÖTH, 1995). 
Os termos mais empregados no estudo dos signos são semiótica e semiologia, apesar de derivados da mesma raiz etimológica, por algum tempo, esses termos costumavam ser identificados como as "duas tradições". A tradição lingüística de Saussure, Hjelmslev e Barthes era geralmente definida como semiologia. A teoria geral dos signos na tradição de Peirce e Morris era chamada de semiótica. Hoje, a semiótica é geralmente aceita como sinônimo de semiologia ou como um termo mais geral, que inclui a semiologia como um dos seus ramos (NÖTH, 1995; ECO, 2009). No contexto filósofico, há relatos históricos do estudo dos signos e significados desde as reflexões da origem da linguagem no dialógo "Crátilos" de Platão (427 - 347 a.C) e na "Poética sobre Interpretação" de Aristóteles (384 - 322 a.C), passando pela Teoria Estóica de Zenão de Cítio (333 - 263 a.C) e Crísipo de Solis (280 - 208 a.C) (NÖTH, 2008; SANTAELLA, 1983).

Ao longo do tempo outros pensadores também se dedicaram ao estudo dos signos, entretanto, a primeira menção ao termo "Semiótica" é feita por Jonh Locke em 1690, porém a sua adoção defintiva foi dada por Morris, como explicita Nöth (1995):

The first explicit mention of semiotics as a branch of philosophy is in Locke's Essay Concerning Human Understanding where the

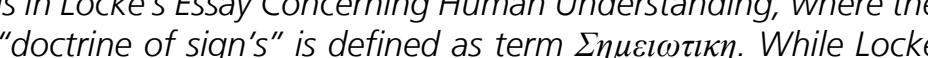
only proposed this term without himself using it systematically the word reappears more frequently in the writings of Johann Heinrich Lambert (1764). The second volume of his Neues Organon is entitled Semiotik [Semiotics, or the Doctrine of the Designation of Ideas and Things]. The tradition of explicit semiotic philosophy was continued by Bolzano (173 a.C), who deals

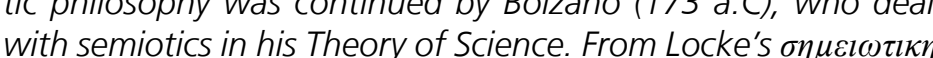
Peirce adopted the term semeiotic. Sometimes he uses the form semiotic or semeiotics, rarely semeotic, but never semiotics. Semiotic is the form adopted by Morris (NÖTH, 1995, p. 13).

No século $\mathrm{XX}$ a semiótica se desenvolveu sendo os seus principais expoentes Peirce, Morris, Saussure, Hjelmslev, e Jakobson. Estes autores tiveram seus respectivos estudos conhecidos como Clássicos da Semiótica Moderna (DEELY, 2015), os quais deram origem à posições filosóficas e científicas para a Semiótica discutidas por diversos pesquisadores nos Estados Unidos, Europa e Brasil.

O campo de pesquisa da semiótica encontra-se em toda forma de linguagem, como explica Santaella (1983, p. 02), "a semiótica é a ciência que tem por objeto de investigação todas as linguagens possíveis, ou seja, que tem por objetivo o exame dos modos de constituição de todo e qualquer fenômeno como fenômeno de produção de significação e de sentido". Devido ao fato da semiótica investigar explicitamente todos os signos, as relações sígnicas e as operações sígnicas, que são usadas implícita, intuítiva e automaticamente Morris (1994) e Santaella (1983) acreditam ser ela a base da compreensão das principais formas da atividade humana, pois oferece uma linguagem geral, aplicável a qualquer outra forma de comunicação e, consequentemente, aplicável à linguagem de toda e qualquer ciência.

Contudo, Eco (2009) adverte que uma teoria geral da semiótica deve reconhecer, estabelecer e respeitar limites naturais e políticos para que se possa identificar o seu objeto de estudo que é o signo. Tal advertência também é respaldada por Santaella (1983):

...embora a Semiótica se constitua num campo intrincado e heteróclito de estudos e indagações que vão desde, a culinária até a psicanálise, que se intrometem não só na meteorologia como também na anatomia, que dáo palpites tanto ao cientista político quanto ao músico, que imprevistamente invadem territórios que se querem bem protegidos pelas bem demarcadas fronteiras entre as ciências, isso não significa que a Semiótica esteja sorrateiramente chegando para roubar ou pilhar o campo do nômenos, sejam eles quais forem - uma nesga de luz ou um nômenos, sejam eles quais forem - uma nesga de luz ou um da ciência - a Semiótica busca divisar e deslindar seu ser de linguagem, isto é, sua ação de signo. Tão só e apenas. E isso já é muito (Santaella, 1983 p. 3)

Considerando a abrangência do campo de pesquisa da semiótica Morris (1994, p. 24) afirma a existência de uma dupla conexão entre os signos e a ciência, "es una ciencia más y a la vez un instrumento de las ciencias". Na concepção do autor, cada ciência utiliza e expressa seus resultados por meio dos signos, daí se origina um campo vasto de utilização e aplicação da semiótica. Por sua característica multidisciplinar, a semiótica oferece uma forma de linguagem aplicável à compreensão de outras ciências, por isso, pesquisadores de diversas áreas têm utilizado a semiótica em suas pesquisas. Nesse sentido, a contabilidade também tem sido investigada pela perspectiva da semiótica por guns pesquisadores, como será demonstrado a seguir.

\section{Semiótica em Contabilidade}

No contexto organizacional, a semiótica possibilita a compreensão das organizações por meio de documentação e comunicaç̃̃es como os signos, baseando-se no conceito de signo de Peirce (SARBO; YANG, 2016). Por sua vez, as informações documentais e escritas são formas de comunicação da contabilidade para seus diversos usuários.

Crowther (2018) argumenta que nos relatórios corporativos a suposição mais comum é que a parte mais significativa e relevante seja tida pelas informações contábeis, mas as mudanças do ponto de vista da administração e de responsabilidade passaram a considerar diferentes perspectivas de desenvolvimento voltadas para o futuro e para a sociedade como uma abordagem mais alternativa. Nessa perspectiva de informações mais significativas, a 
contabilidade fornece base para considerar a semiótica como forma contributiva de identificar informações adicionais e relevantes nos relatórios corporativos, pois fornece insights úteis para estudar a mensagem. (CROWTHER, 2018; MERKL-DAVIES; BRENNAN, 2017)

No contexto de troca de informações, a semiótica considera a comunicação como um processo de produção e troca de significados entre emissor e receptor, com o objetivo de produzir e gerar conhecimento, e não como um mero processo de transmissão de mensagens (VASILE et al, 2009). Na expectativa de explicar o papel da semiótica no contexto contábil, Nakagawa e Dias FiIho (2002) argumentam que a semiótica se preocupa com o estudo de todos os tipos de linguagem e, por esse motivo, pode contribuir para a eficácia da evidenciação contábil. Enquanto isso, Tinker (1991) demonstra que a semiótica se estende a todos os sistemas de representação simbólica para comunicação das informações contábeis, não estando atrelado apenas a linguagem mais óbvia e comumente utilizada. Nessa mesma linha de raciocínio, Andriyani (2016) entende a contabilidade como uma linguagem, porque possui símbolos e outras características de linguagem e significados que podem ser identificados em qualquer idioma. Nesse cenário, a semiótica como teoria e análise de vário signos ou símbolos e significados é aplicada em conotações apresentadas nas demonstrações financeiras.

Considerando os argumentos de que a semiótica contribui para o desenvolvimento da comunicação na contabilidade, diversos pesquisadores buscam estudar essa relação. Um exemplo é a dissertação de Etheridge (1991) que propõe o uso da semiótica como instrumento de apoio à avaliação dos aspecto semântico, sintático e pragmático da informação contábil. Em um contexto aplicado, um exemplo é o trabalho de Hronsk (1998), onde um modelo semió tico de atividade comunicativa, desenvolvido em teoria literária para analisar textos escritos é aplicado ao relatório de auditoria. Isso assemelha-se a Nakagawa e Dias Filho (2012), que apresentam a semiótica como contribuição para o aprimoramento dos processos de análise de balanços.

Com foco na formação profissional, llufi (2000) defende a idéia de que a Teoria da Semiótica e a Teoria da Comunicação devem ser incorporadas ao processo de formação universitária do contador no Chile. Nesse mesmo sentido, Nakagawa e Pretto (2000) propõem uma mudança no perfil do profissional contábil em relação a linguagem e comunicação contábil, considerando esta como provedora de informações para tomada de decisão como linguagem dos negócios, torna-se importante para os profissionais contábeis a in tegração dos conceitos de contabilidade com as teorias da comunicação com ênfase na teoria da semiótica. Na área pública, um exemplo é a dissertação de Messias (2017), que orientado pelas Teorias da Comunicação e da Semiótica estudou os ruídos presentes no processo de comunicação contábil através de um estudo de caso qualitativo na Universidade Federal da Integração Latino -Americana (Unila).
Como se observa nos exemplos supracitados, diversas investigações científicas que relacionam a contabilidade com a semiótica vêm sendo desenvolvidas ao longo do tempo, mas também é possível pensar na semiótica como uma abordagem epistemológica que poderia auxiliar nessas investigações, como será discutido nesse artigo.

\section{A Semiótica de Pierce como uma Posição Epistemológica}

Em linhas gerais a semiótica de Peirce pode ser entendida como o estudo do modo como o ser humano reconhece e interpreta o mundo à sua volta. As coisas do mundo real ou abstratas, primeiro surgem na mente como qualidade, depois como relação com algo já conhecido e por fim a mente faz a interpretação para explicar do que se trata. Dessa forma, a semiótica se baseia numa tríade de classificações e inferências, ao demonstrar que existem os objetos no mundo, suas representações em forma de signos e a interpretação mental desses objetos, ao que Peirce chamou de Primeiridade, Secundidade e Terceiridade. E todo esse processo é feito pela mente a partir dos signos que compõem o pensamento e que se organizam em linguagens (NÖTH, 1995; SANTAELLA, 1983; SILVA, 2015; WASIK, 2014).

Assim, o primeiro ponto a ser discutido dentro do aspecto epistemológico é a própria discussão sobre a possibilidade da semiótica ser vista como tal, nesse sentido Kremer (1994) afirma:

$$
\begin{aligned}
& \text { Peirce opened a paved way in which epistemology is linked to } \\
& \text { a theory of meaning and a theory of signs. Indeed, the general } \\
& \text { concern of epistemology is the question of what knowledge is } \\
& \text { and how it is possible. Epistemology seeks to answer the ques- } \\
& \text { tion: How can humans know about the natural world? Peirce } \\
& \text { gave his answer: only through the way of signs considered as } \\
& \text { tools and objects. Signs are not only linguistic, but also logical } \\
& \text { and pragmatic (KREMER, 1994, p. 110). }
\end{aligned}
$$

Nesse mesmo sentido, Silva (2015) utiliza o posicionamento anárquico de Feyeraband para argumentar que, mesmo rompendo com as formas tradicionais de conhecimento, a semiótica pode ser fundada em uma sólida epistemologia. Assim como Santos (2001) que afirma ser a semiótica uma contribuição fundamental a epistemologia, ao mesmo tempo em que se contrapõe a outros modelos epistemológicos da filosofia moderna e contemporânea.

No entanto, algumas críticas são levantadas contra a epistemologia de Peirce. dentre elas, o fato de desafiar o princípio de que a mente humana está adaptada à natureza, em virtude da postulação do incognoscível, seja devido a uma materialidade localizada aquém de qualquer representatividade ou uma transcendência inatingível por qualquer representação. E também ao fato de Pierce adotar um sistema de categorização, que aos olhos dos críticos 
parece ser muito especulativo (DAVIS, 1972; KREMER, 1994; SANTOS, 2001). Tais críticas, porém são rebatidas pelos pesquisadores supracitados que demonstram a essência epistemológica do trabalho de Pierce.

Dentro da proposta de apresentação da semiótica peirceana como epistemologia o caminho para o entendimento pode ser iniciado pela fenomenologia ou faneroscopia, como ele prefere chamá-la, para evitar confusões conceituais, visto que Peirce parte da fenomenologia para chegar nas Ciências Normativas, que são à Estética, à Ética e à Lógica ou Semiótica. Na visão de Peirce, a gênese de todo o conhecimento é a observação do fenômeno e a posterior análise da experiência através da categorização do pensamento dos objetivos (SANTAELLA, 1983; KREMER, 1994; SANTOS, 2001).

Embora essa visão possa, a princípio, parecer muito próximo do método do conhecimento Aristotélico que parte da observação em direção à definição para demonstrar verdade; ao contrário deste, Peirce voltou-se para elaboração de categorias universais sem se preocupar com pressupostos de validação, como explica Santaella (1983):

A fenomenologia peirceana começa, pois, no aberto, sem qualquer julgamento de qualquer espécie: a partir da experiência ela mesma, livre dos pressupostos que, de antemão, dividiriam os fenômenos em falsos ou verdadeiros, reais ou ilusórios, certos ou errados. Ao contrário, fenômeno e tudo aquilo que aparece mente, corresponda a algo real ou não (SANTAELLA, 1983, p. 7).

A partir do modo como o fenômeno aparece para a consciência, Peirce classifica os fenômenos em três classes ou modos de ser da experiência, que constituem categorias denominadas: primeiridade, segundidade e terceiridade.

A primeiridade é a qualidade da consciência imediata é uma impressão, algo totalmente distinto de qualquer relação ou comparação, formando uma unidade em si mesmo. É constituído de experiências imediatas, que contêm as qualidades de sentimento percebidas do fenômeno. A segundidade compreende o domínio da experiência, da realidade, da ação da coisa ou evento. É a sensação que se distingue do sentimento por ser composta pelo próprio sentimento e pela inerência desse sentimento num sujeito; o fenômeno reage à consciência, para se firmar como indivíduo, como isto e não aquilo. A terceiridade corresponde à camada de "inteligibilidade", ou pensamento em signos, através da qual representamos e interpretamos o mundo. Produz a percepção da realidade exterior (SANTAELLA, 1983; SANTOS, 2001).

Essa visão fenomenologica conduz a uma reflexão sobre a forma como Peirce se despia de pré-conceitos ou pré-juízos que um aporte teórico daria à construção do conhecimento, trazendo à tona a ideia de que uma fenomenologia natural da mente leva à crença e à regra e ao hábito do pensamento como ação mental. E essa originalidade da epistemologia de Peirce, na visão de Kremer (1994), dá conta da realidade e legaliza a comunicação científica. Outro aspecto que clarifica a idéia de uma epistemologia semiótica é a concepção de signo vinculada à lógica, que parte de uma organização triádica, formada por signo, objeto e interpretante, em que cada um desempenha uma função a produção de significado. Segundo Silva (2015, p. 61), "a grande ruptura paradigmática promovida pela epistemologia semiótica está na relação sujeito/objeto. Num mundo de mediação, esta não se encontra mais resolvida nos termos definidos pela ciência tradicional, ganhando novos contornos que ampliam consideravelmente o seu grau de complexidade."

De fato, em sua teoria Pierce apresenta um signo, ou representamên, como aquilo que, sob certo aspecto ou modo, representa algo para alguém. Dirige-se a alguém, isto é, cria, na mente dessa pessoa, um signo equivalente, ou talvez um signo mais desenvolvido. A partir dessa definição três pólos são encontrados: 1) a face perceptiva do signo, "representamêm"; 2) o que ele representa "objeto"; 3) e o que significa "interpretante" ou significado - o que ocorre na mente do interprete (SANTOS, 2001).

Dessa forma, a concepção de sujeito é afetada pela destituição da noção cartesiana de indivíduo pleno que aprende e um objeto que se permite conhecer, e substituída por uma cadeia ininterrupta de processos de mediação e produção de significados, pela introdução da função mediadora do signo, em cujo processo indivíduos particulares não deixam de encontrar um lugar, mas trata-se de um lugar dentro da tríade do signo-objeto-interpretante capazes de levar à entender as minúcias dos processos interpretativos e cognitivos que os signos instauram (SANTAELLA, 1983; SILVA, 2015). Ainda um terceiro aspecto a ser considerado dentro da posição da semiótica como epistemologia é o raciocínio em que é formado o processo de conhecimento, especialmente no que concerne à Indução, Abdução e Dedução, formando uma nova tríade na verificação dos fatos e na lógica do raciocínio.

A Abdução ou Retrodução é uma espécie de intuição é a busca de uma conclusão pela interpretação racional de sinais, de indícios, de signos. Como lógica do levantamento de hipóteses, fornecerá os dados iniciais ou premissas, cabendo a Dedução completar a construção, pelas conseqüências necessárias dos fatos, ou pela simples constatação de propriedades contidas na construção do raciocínio, mas não enunciadas na hipótese. Caberá, por sua vez, a Indução produzir as estratégias de verificação experimental das conclusões obtidas nas hipóteses testadas, diferentemente de sua condição na ciência tradicional (SANTAELLA, 1983; KREMER, 1994).

Na visão de Silva (2015), a interpretação através da teoria geral dos signos e as tríades lógicas de Peirce, quando relacionadas ao contexto científico, sedimentam o arcabouço teórico da epistemologia semiótica. $\mathrm{O}$ autor ainda argumenta que a semiótica como modelo epistêmico já está estabelecida, gerando novos processos de organização e significação, implicando uma proposta renovada de ciência, marcada pela diferença e complexidade. 
5 A Semiótica como uma Alternativa Epistemológica em

\section{Contabilidade}

Tendo em vista que a contabilidade envolve o processo de comunicação de informações para diversos stakeholders, a semiótica desenvolve-se como uma alternativa específica a nível epistemológico dentro do processo de comunicação de informações pela contabilidade sob uma perspectiva socialconstrucionista da organização e suas comunicações (ETHERIDGE, 1991; PÄRL, 2011). Mais especificamente, a semiótica de Pierce fornece uma visão geral para compreensão abrangente da informação que possibilita a percepção de objetos da informação como signos com caraterísticas ontológicas e epistemológicas (THELLEFSEN, et al, 2017).

Considerando que os signos possuem ação fundamental de gerar sempre novas e diferentes interpretações, a epistemologia semiótica busca apresentar novas formas interpretativas sem ocultar as demais epistemologias (SILVA, 2015). Dessa forma, tendo os símbolos, significados e signos como alternativas para a criação de novos caminhos e quebra de paradigmas científicos, a chamada mudança de paradigma. Assim, Thellefsen e outros (2017) discutem a semiótica peirciana como uma teoria abrangente da informação, considerando que a informação é o que faz iniciar qualquer processo de criação de significado. Nesse mesmo sentido, Pärl (2011) propõe uma teoria baseada na semiótica como uma alternativa para auxiliar as organizações na melhoria das práticas e processos de contabilidade gerencial e sistemas de controle, bem como no envolvimento de funcionários e gerentes das organizações.

Para Merkl-Davies e Brennan (2017), a tradição semiótica, dentre outras diversas tradições, faz parte de uma maneira alternativa de conceituar a comunicação contábil com o público externo por meio de documentos públicos que não sejam as demonstrações financeiras auditadas, tais como relatório anuais, relatórios de responsabilidade social e sites. Tal tradição semiótica faz parte da perspectiva narrativa simbólica-interpretativa da comunicação contábil interativa, utilizando a teoria dos signos e sinais para comunicação. Segundo Gouveia (2010), um exemplo ilustrativo de como utilizar uma teori semiótica para analisar a produção de significados de demonstrações contábeis pode ser considerado com a proposta de FIPECAFI para apresentação da DOAR, Demonstração das Origens e Aplicaç̃̃es de Recursos, a partir da teoria semiótica desenvolvida por Charles Peirce.

Como se observa, a semiótica é considerada por alguns pesquisadores da área contábil como uma alternativa epistemológica dentro do processo comunicativo na contabilidade, seja através de uma perspectiva sócio-construcionista, seja através de uma perspectiva simbólica-interpretativa; ou mesmo como uma perspectiva própria de abordagem. Um exemplo de investigação utilizando uma abordagem semiótica é a pesquisa realizada por Pratiwi e Haq
(2015) onde os autores apresentam a contabilidade como uma realidade econômica e religiosa no contexto bancário islâmico. Por meio de uma análise sob a perspectiva da semiótica, os autores mostraram que o relatório contábil das empresas do setor bancário islâmico da Indonésia contém valores religiosos pela forma como as imagens e fotografias dos relatórios anuais são apresentados.

Outro exemplo é o trabalho de Yekini, Burrows e Omoteso (2014), em que os autores investigam a qualidade e veracidade da Responsabilidade Social Empresarial na divulgação dos relatórios anuais, para tal o estudo utilizou como ferramenta analítica a semiótica. $O$ estudo revelou que a significação da realidade é duvidosa ou irreal para a maioria das empresas da amostra, assim como produziu um Modelo de Realidade Semiótica que, de acordo com autores, pode ser usado para melhorar a avaliação de divulgação em relatórios corporativos anuais.

Assim, é possível pensar em pesquisas contábeis diversas com abordagem semiótica, como explica Gouveia (2010), há uma variedade de narrativas passíveis de investigação como atas de assembléias, avisos aos acionistas, notas explicativas, parecer de auditores independentes, dentre outros; bem como diferentes objetos de estudo como fluxo de caixa, demonstração de origem e aplicação de recursos, balanço patrimonial, etc. Outro aspecto diversificado é a perspectiva com que o objeto é abordado, tais como: marketing, disclosure e accountability.

\section{Considerações Finais}

O rigor das pesquisas positivistas em contabilidade tem sido questionado, pois os conceitos em que a Contabilidade se baseia são socialmente construídos, não podendo ser medidos e apresentados apenas de maneira quantitativa como ocorre nas ciências naturais, incentivando a busca de caminhos alternativos.

Pesquisas com abordagens alternativas na contabilidade podem ser caracterizadas por uma diversidade metodológica que inclui pesquisa interpretativa e pesquisa crítica, além de uma variedade de métodos de pesquisa tais como trabalho de campo, estudos de caso, análise do discurso, entre outros. $O$ presente estudo teve como propósito discutir a semiótica como uma proposta de alternativa epistemologica nas pesquisas em contabilidade, procurando compreender a forma como a mesma pode ser utilizada para essa finalidade.

Em geral as pesquisas que relacionam a semiótica com a contabilidade trazem duas perspectivas: a contabilidade como uma linguagem informacional, e nesse aspecto a semiótica é vista mais na perspectiva da tridimensionalidade da linguagem (sintática, pragmática e semântica); ou a contabilidade como um processo de comunicação, onde se relaciona a teoria da comunicação com a teoria da semiótica trazendo à ideia emisor, mensagem, receptor. Entretanto, o 
entendimento do estudo dos signos é muito mais abrangente. A semiótica na filosófia de Peirce é entendida de forma mais global como uma posição epistemologica, na qual os principais argumentos de defesa são: a fenomenologia classificada em categorias (primeiridade, segundidade e terceiridade); a ruptura paradigmática sujeito-objeto com através dos três pólos ("representamêm," objeto e interpretante); e a lógica do raciocínio (abdução, dedução, indução).

Na contabilidade, essa visão da semiótica como uma abordagem epistemológica, embora pouco discutida, tem sido considerada sob três perspectivas: sócio-construcionista, simbólica-interpretativa e como uma abordagem própria. Baseado nesse entendimento, algumas pesquisas já utilizam a semiótica como uma alternativa para criação de modelos de investigação científica. Baseando-se nos aspectos discutidos e apresentados nesse artigo, é possível posicionar a semiótica como uma abordagem alternativa de pesquisa, de forma que essa seja considerada como uma iniciativa que reconheça a contabilidade dentro do contexto sociológico e que observa as caraterísticas intrínsecas à realidade dos fenômenos contribuindo para o progresso científico contábil. Considerando as contribuições sociológicas que o estudo dos signos pode trazer para contabilidade, sugere-se a expansão de pesquisas na área através de reflexões teóricas sobre aplicações da semiótica como abordagem de pesquisa em contabilidade gerencial, finanças, governamental, entre outras; bem como, desenvolvimento de modelos e aplicações práticas.

\section{Referências}

Andriyani, F. Modern Camera Connotations: Semiotics Profit Accounting in Perspective Roland Barthes. In: INTERNATIONAL CONFERENCE ON EDUCATION, 284-291, 2017

Crowther, D. A Social Critique of Corporate Reporting: A Semiotic Analysis of Corporate Financial and Environmental Reporting. London, Routledge, 2018

Davis W. H. Peirce's Epistemology. The Hangue, Nijhoff, 1972 Deely, J. Chapter 2 Semiotics "Today": The Twentieth-Century Founding and Twenty-First-Century. In: Internationa
Handbook of Semiotic. Editors: Trifonas, Peter Pericles, 2015.

Dias Filho, J. M. A Contabilidade e a Ordem Social: Uma abordagem das teorias semióticas e da comunicaçãa. Revista da FAE, v.16, n.1, p. 6-17, 2013

Eco, U. Tratado Geral de Semiótica (Danesi, A. P. \& Souza, G. C. C., Trad.). 4a ed. São Paulo, Perspectiva, 2009

Etheridge, H. L. An examination of Semiotic Theories of Accounting Accruals. Louisiana State University, 1991. Dissertation (Unpublished Ph.D), Baton Rouge, Luisiana, United States.

Fontana, F. B., Diehl, C. A., Souza, M. A., \& Macagnan, C. B. Um Estudo sobre as Publicaçöes Contábeis sob o Foco da Semiótica. Revista de Educação e Pesquisa em Contabilidade, v. 7, n. 1, p. 5-19, 2013

Gouveia, F. H. C. (2010) Uma incursão pela abordagem de pesquisa em contabilidade no Brasil fundamentada em teorias semióticas e da comunicação. São Paulo, 2010. Dissertação (Mestrado em
Contabilidade). Universidade de São Paulo.

Hopwood, A. J. Whither accounting research? The Accounting Review, v. 82, n. 5, p.1365-1374, 2007

Hronsky, J. J. F. Signs, Codes and Communication: The Semiotics of Audit Reports. Camberra: National Library of Australia Collection, 1998.

Sh REVISTA SOCIAIS \& HUMANAS - VOL. 32 / № 3 - 2019 llufi, O. M. V. Teoria da Comunicação e Teoria da Semiótica: Sua Incorporação ao Processo de Formação Universitária do Contador no Chile. In: CONFERENCIA ACADÉMICA PERMANENTE DE PESQUISA EM CONTABILIDADE XI ASSEMBLÉIA ANUAL, Talca, Chile, 2000. Anais.

Kremer M. A. Peirce's Epistemology as a Generalized Theory of Language. In: Debrock G., Hulswit M. (eds.) Living Doubt. Synthese Library (Studies in Epistemology, Logic, Methodology, and Philosophy of Science). Dordrecht, Springer, 1994

Major, M. J. O positivismo e a pesquisa 'alternativa' em Contabilidade. Revista Contabilidade \& Finanças-USP, v. 28, n. 74, p. $173-178,2017$

Merkl-Davies, D. M., \& Brennan, N. M. A theoretical framework of external accounting communication: Research perspectives, traditions, and theories. Accounting, Auditing \& Accountability Journal, v. 30, n.2, p. 433-469, 2017

Messias, D. A informação contábil no setor público: uma abordagem sob a ótica das teorias da comunicaçao e da semiotica. Cascavel, 2017. Dissertação (Mestrado em Contabilidade). Universidade Estadual do Oeste do Paraná.

Morris, C. Fundamentos de la Teoria de los Signos. 2a ed. Barcelona, Ediciones Paidós Ibérica, 1994.

Nakagawa, M., \& Dias Filho, J. M. A Contabilidade sob o enfoque sociológico: uma abordagem das teorias semióticas e da comunicação. Augusto Guzzo Revista Acadêmica, v. 5, p. 13-22, 2002.

Nakagawa, M., \& Dias Filho, J. M. Reflexōes sobre a Dimensão Semiótica da Análise de Balanços: Uma Contribuição a Otimização de Decisões de Crédito. Revista de Contabilidade da UFBA, v. 6, n.1, p. 33-47, 2012.

Nakagawa, M., \& Pretto, C. B. M. An interdisciplinary view of accountancy in Brazil. In: ASIAN-PACIFIC CONFERENCE ON INTERNATIONAL ACCOUNTING ISSUES, China, 2000. Anais... 12.

Nöth, W. Handbook of semiotics Enlarged translation of: Handbuch der Semiotik. Indianapolis, Indiana University Press, 1995

a Peirce. Sáo Paulo, Annablume, 2008.

Pärl, Ü. A semiotic alternative to communication in the processes in management accounting and control systems. Sign Systems Studies, v. 39, n. 1, p. 183-208, 2011

Pratiwi, R. N., \& Haq, M. S. Accounting as Economic and Religious Reality: Reveal Religious Values Through the INTERNATIONAL CONFERENCE ON ARABIC

Santos, J. F. Semiótica e Epistemologia em Charles Pierce: uma abordagem introdutória. Revista de Educação da Univali - Contrapontos, v. 3, n.1, p. 95-108, 2001

Sarbo, J. J., \& Yang, J. H. Vitalizing Semiotics. In: INTERNATIONAL CONFERENCE ON INFORMATICS AND SEMIOTICS IN ORGANISATIONS, Campinas, SP, Brasil, 2016. Anais... 17.

Silva, V. L. Semiótica e Epistemologia: A Ciência como Processo. Pensando-Revista de Filosofia, v. 6, n.12, p. 5768,2015

Thellefsen, M. M., Thellefsen, T., \& Sørensen, B. Information as signs: A semiotic analysis of the information concept, determining its ontological and epistemological foundations. Journal of Documentation, v. 74, n.2, p. 372-382, 2017.

Tinker, T. The accountant as partisan. Accounting, Organizations and Society, v. 16, n.3, p. 297-310, 1991.

Vasile, P., Aristita, R., Cristina, C. A., \& Mihaela, L. Accounting-A semiotic process. Economic Science, v. 3, n.1, p. $1105-1112,2019$

Walker, S. P. Revisiting the roles of accounting in society. Accounting, Organizations and Society, v. 49, n.2, p. $41-50,2016$

Wasik, Z. Lectures on the Epistemology of Semiotics. Wroc-aw: Philological School of Higher Education in Wroc aw Publishing/Philologica Wratislaviensia, 2014 
A SEMIÓTICA COMO ALTERNATIVA EPISTEMOLÓGICA NAS PESQUISAS EM CONTABILIDADE

Williams, P. F. The myth of rigorous accounting research. Accounting Horizons, v. 28, n.4, p. 869-887, 2014.

Yekini, K. C., Burrows, L., \& Omoteso, K. A Semiotic approach to evaluating the quality and veracity of CSR reporting. Accounting and Finance Occasional Paper Series. v.2, p. 2-30, 2014. 